\title{
A PANDEMIA COVID-19 EM PORTUGAL CONTINENTAL - UMA ANÁLISE GEOGRÁFICA DA EVOLUÇÃO VERIFICADA NOS MESES DE MARÇO E ABRIL
}

\section{COVID-19 IN PORTUGAL - A GEOGRAPHICAL ANALYSIS OF MARCH-APRIL EVOLUTION}

\author{
Eduarda Marques da Costa \\ Prof. Associada do Instituto de Geografia e Ordenamento do Território \\ Universidade de Lisboa \\ eduarda.costa@campus.ul.pt
}

Nuno Marques da Costa

Prof. Auxiliar do Instituto de Geografia e Ordenamento do Território

Universidade de Lisboa

nunocosta@campus.ul.pt

\begin{abstract}
RESUMO
O processo de difusão do vírus pelos vários países e regiões do mundo, vem destacar a importância da geografia na interpretação dos fenómenos. O presente artigo tem como objetivo identificar a evolução concelhia da propagação do vírus COVID-19, no período compreendido entre março e abril em Portugal Continental, procurando relacionar esse padrão com as características demográficas e socioeconómicas do território continental português. O processo de difusão iniciou-se pelas áreas urbanas mais densas, seguindo as áreas de fronteira e posteriormente, propagou-se aos territórios de população envelhecida e menor densidade demográfica.
\end{abstract}

Palavras-chave: COVID-19. Difusão espacial. fatores sociodemográficos.

\begin{abstract}
The process of spreading the virus across countries and regions around the world, highlights the importance of geography in interpreting the phenomena. This article aims to identify the evolution of the phenomena in Portugal, between March and April, seeking to relate this pattern to the demographic and socio-economic characteristics of the territory. The diffusion process starts by the metro areas and other densely urbanised territories, follows to boarder areas and finally went to ageing and less dense territories.
\end{abstract}

Key words: COVID-19. Spatial diffusion. Socio-demographic factors.

\section{INTRODUÇÃO}

Em 2019, a OMS apresentou uma lista revista do que considerou serem as dez grandes ameaças globais. Entre estas, contavam-se as pandemias decorrentes do vírus influenza, da expansão do ébola e de outros agentes patogénicos de alto-risco, a resistência aos antibióticos, o dengue e a resistência à vacinação (WHO, 2019). Por outro lado, a OMS destaca que estas ameaças ganham importância adicional nas áreas urbanas, onde reside cada vez mais população. Os primeiros registos associados à infetados com o vírus COVID-19 ocorreram em finais de dezembro na China, relacionados ao, agora mundialmente famoso, mercado de frutos do mar Huanan em Wuhan. A partir desta cidade, assistimos à difusão deste vírus pelo mundo, originando o processo pandémico. Em finais de dezembro, as análises realizadas a amostras de lavagem bronco alveolar recolhidas de um paciente com pneumonia de etiologia desconhecida no Hospital Wuhan Jinyintan permitiram identificar um vírus associado à estirpe de coronavírus tipo SARS. É neste

Recebido em: 02/05/2020

Aceito para publicação em: 17/05/2020. 
contexto que o vírus é oficialmente chamado SARS-CoV-2 devido à sua semelhança com o coronavírus da Síndrome Respiratória Aguda Grave.

O processo de difusão mundial do vírus vem destacar a importância da geografia na interpretação destes fenómenos, tal como outros estudos associados a processo de difusão evidenciaram.

O presente artigo tem como objetivo apresentar a evolução concelhia da propagação do vírus COVID-19, no período compreendido entre 23 de março e 25 de Abril em Portugal Continental, procurando relacionar o padrão de difusão com as características demográficas e socioeconómicas do território continental português.

O artigo estrutura-se em cinco partes. A primeira parte corresponde à presente introdução, a que se segue uma segunda parte onde se procede à descrição de dados e métodos utilizados. Na terceira parte, analisase a posição de Portugal no quadro mundial a partir da leitura do $n^{\circ}$ de casos confirmados. Na quarta parte, analisa-se a distribuição regional do número de casos e a sua relação com o contexto demográfico e socioeconómico de Portugal Continental. A quinta e última parte, correspondem a breves conclusões.

\section{DADOS E MÉTODOS}

A informação sobre a evolução do número total de casos confirmados e número total de óbitos por país, encontra-se disponível no dashboard da OMS (WHO, 2020), havendo um outro website que disponibiliza informação para o continente europeu. Na OMS-Europa, para além do número total de casos confirmados e o número total de óbitos, encontramos uma discriminação do número de casos confirmados e óbitos ocorridos nos últimos 7 dias, bem como a representação gráfica do número de novos casos e de óbitos diários (WHO 2020b). No ponto 3 do presente artigo usaremos alguma informação que permita posicionar Portugal no contexto mundial e europeu.

A parte 4, centra-se sobre a análise de Portugal, tendo em conta, não só os dados agregados, mas também pela informação disponibilizada diariamente por concelho pela Direção Geral de Saúde, num portal com dados atualizados diariamente, em simultâneo com a publicação de boletins epidemiológicos diários. O Portal da DGS (https://covid19. min-saude.pt/ponto-de-situacao-atual-em-portugal/) disponibiliza informação sobre o número total de casos confirmados, recuperados, óbitos e casos suspeitos, para o país e por regiões, sendo ainda possível obter o número total de casos confirmados ao nível concelho.

Esta informação por concelho, é de grande interesse para o acompanhamento da propagação do fenómeno. Contudo, temos três limitações: a primeira informação ao nível do concelho surge disponível pela $1^{\mathrm{a}}$ vez a 23 de março, sendo que os primeiros casos de COVID-19 foram registados em Portugal a 2 de março; a segunda limitação decorre da necessidade de garantir a confidencialidade estatística, apresentando-se apenas valores para os concelhos com 3 ou mais casos; a terceira, relaciona-se com o método de recolha de informação e os problemas inerentes ao confronto de duas bases de registo, onde ocorrem por vezes duplas contabilizações, que acabam sempre por ser corrigidas passados dois a três dias. No entanto, apesar destas limitações a informação constitui um bom referencial para avaliar a difusão do fenómeno.

Partindo do único dado diário disponível ao nível concelhio - número de casos confirmados, determina-se o número de casos/10 000 habitantes, o que corresponde à taxa de prevalência.

\section{ENQUADRAMENTO DE PORTUGAL NO CONTEXTO INTERNACIONAL}

A 31 de março, registavam-se 719758 casos confirmados e 33673 mortos em 202 países, valores que em 1 de abril, subiram para 823626 casos confirmados e 40598 mortos em 203 países. Entre 3 e 12 de abril, os dados mundiais da evolução da pandemia COVID-19 registaram um acréscimo acentuado; o número de casos confirmados cresceu 81,9\% (976 586 em 03 de abril para 1776867 em 12 de abril) e o número de mortes aumentou 121,5\% (37 119 mortes em 3 de abril para 77438 a 12 de abril). A 12 de Abril, os EUA representavam $29,5 \%$ dos casos confirmados (524514) e 18,3\% das mortes (20 444) mundiais (MARQUES DA COSTA, MARQUES DA COSTA, 2020b).

O continente europeu, com 424515 casos confirmados e 26701 mortos registados em 53 países no dia 31 de março, viu subir os valores para 464859 casos e 30098 mortos em 1 de abril. Este valor representava em 1 de abril, $56 \%$ dos casos diagnosticados no Mundo, números que são liderados pela Itália, a Espanha e a Alemanha. Portugal ocupava nessa altura o $11^{\circ}$ lugar no conjunto dos países Europeus. Em finais de abril, mais precisamente a 28 de abril, Portugal ocupava o $10^{\circ}$ lugar em número de casos, mas apresentava uma situação mais positiva quando analisamos o número de óbitos/milhão de habitantes (93, por DOI:http://dx.doi.org/10.14393/Hygeia0054396 $\quad$ Hygeia $\quad$ Edição Especial: Covid-19, Jun./2020 p.72 - 79, pág. 73 
contraponto à Espanha e Itália, com 510 e 453, respetivamente). Por outro lado, encontramos um novo indicador positivo: o número de testes/milhão de habitantes é dos mais elevados (37 223) só comparáveis com a Itália (30 547), onde o surto pandémico apresenta, pelo menos, 2 semanas de avanço em relação a Portugal. Sendo este o referencial de evolução de Portugal no contexto mundial e europeu, importa agora explorar a sua distribuição pelo território no sentido de procurar a sua relação com a distribuição da população e das atividades económicas.

\section{A PROPAGAÇÃO DO FENÓMENO EM PORTUGAL}

A análise da distribuição do número de casos por concelho, levantados nos dias 23 de março até finais de abril mostra a velocidade da expansão do fenómeno e a sua penetração para o interior a partir das principais cidades e eixos urbanos do litoral. Na presente análise importa cruzar dois padrões: o espacial e o temporal. Assim, o fenómeno permite encontrar 4 padrões de evolução em várias datas.

O primeiro, corresponde ao início do fenómeno e sua difusão. Os primeiros registos reportam ao Porto e Lisboa. No dia 2 de março temos dois casos importados (de Itália e Espanha) confirmados e no dia 3 de março, passamos a 4 casos, sendo que para além de das regiões de Lisboa e Porto, se junta também a área de Coimbra. A 8 de Março surge o $1^{\circ}$ caso na Região do Algarve e só a 17 de março vamos ver surgir o $1^{\circ}$ caso na Região do Alentejo, território interior de menor densidade populacional (MARQUES DA COSTA, MARQUES DA COSTA, 2020a).

Tabela 1 - Distribuição regional dos primeiros casos de COVID-19 em Portugal Continental (2-17 março)

\begin{tabular}{|c|c|c|c|c|c|c|c|c|c|c|}
\hline Região & $\begin{array}{c}2 \text { de } \\
\text { Março }\end{array}$ & $\begin{array}{c}3 \text { de } \\
\text { Março }\end{array}$ & $\begin{array}{c}4 \text { de } \\
\text { Março }\end{array}$ & $\begin{array}{c}5 \mathrm{de} \\
\text { Março }\end{array}$ & $\begin{array}{c}6 \text { de } \\
\text { Março }\end{array}$ & $\begin{array}{c}7 \text { de } \\
\text { Março }\end{array}$ & $\begin{array}{c}8 \mathrm{de} \\
\text { Março }\end{array}$ & $\begin{array}{c}9 \text { de } \\
\text { Março }\end{array}$ & $\ldots$ & $\begin{array}{l}17 \text { de } \\
\text { Março }\end{array}$ \\
\hline Norte & 2 & 2 & 3 & 5 & 8 & 15 & 22 & 27 & $\ldots$ & 289 \\
\hline Centro & & 1 & 1 & 1 & 1 & 1 & 1 & 1 & $\ldots$ & 74 \\
\hline Lisboa & 1 & 1 & 2 & 3 & 4 & 5 & 6 & 9 & $\ldots$ & 243 \\
\hline Alentejo & & & & & & & & & $\ldots$ & 2 \\
\hline Algarve & & & & & & & 1 & 2 & $\ldots$ & 21 \\
\hline
\end{tabular}

Fonte: DGS 2020c: https://covid19.min-saude.pt/ponto-de-situacao-atual-em-portugal/

Face aos números em crescimento muito rápido, no dia 18 de março de 2020 foi decretado o Estado de Emergência em Portugal, através do Decreto do Presidente da República n. ${ }^{\circ}$ 14-A/2020, de 18 de março. No entanto, é de salientar que as atividades letivas do ensino não superior estavam suspensas desde 16 de março e o ensino superior encerrou entre 9 e 13 de março. Tendo em conta a evolução, a Direção-Geral da Saúde (DGS) informa que a fase de mitigação da pandemia da COVID-19 entrou em vigor a 26 de março de 2020 (DGS, 2020b).

A análise apresenta evidências do padrão geográfico do fenómeno associados a fatores socioeconómicos:

\section{Territórios caracterizados por elevadas densidades urbanas e concentração de atividades económicas:}

- numa primeira fase, a evolução do número de casos confirmados até ao dia 1 de abril, apresenta uma forte relação com a densidade populacional, com a estrutura urbana e a localização das principais concentrações de emprego, destacando-se as duas Áreas Metropolitanas e os territórios urbanos que se encontram no seu quadro de relações funcionais, nomeadamente no quadro das deslocações casa-trabalho da população ativa, seguindo o padrão já registado no mês de março. Posteriormente, identifica-se o alinhamento com as ligações viárias e funcionais a Espanha, mais evidente na Região Norte de Portugal (Figuras 3, 4 e 6);

\section{Territórios com forte peso da população envelhecida:}

- Após 1 de abril, o fenómeno expande-se com forte expressão para os territórios do norte e centro interior do território continental, concelhos com menor densidade populacional e com uma população mais envelhecida. Os lares de idosos afirmam-se como focos de infeção, sendo responsáveis por uma parte muito significativa do número de novos casos que emerge de forma dispersa pelos concelhos do interior centro e norte. A análise do número de novos casos por 10000 habitantes e a taxa de casos por 10000 habitantes mostram a importância que o fenómeno regista nestes concelhos que possuem quantitativos populacionais reduzidos. É o caso de Vila Nova de Foz Côa e Castro Daire (Figura 5 e Tabela 2). 
Figura 1 - Número de casos confirmados (concelhos com 3 ou mais casos) $23 / 03 / 2020$ $01 / 04 / 2020$

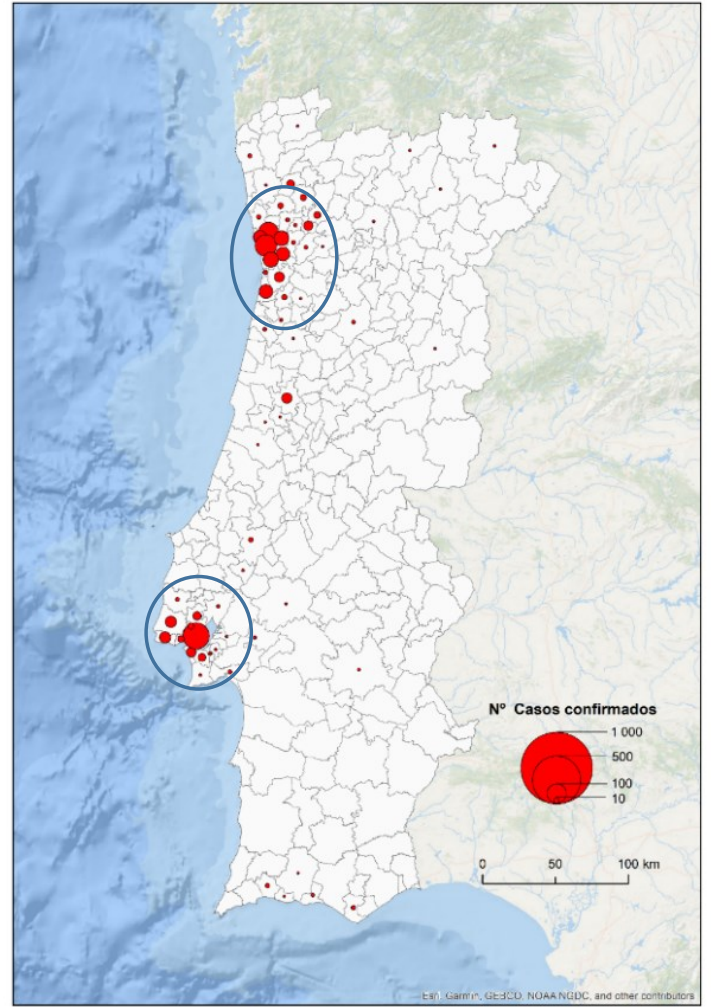

$12 / 04 / 2020$

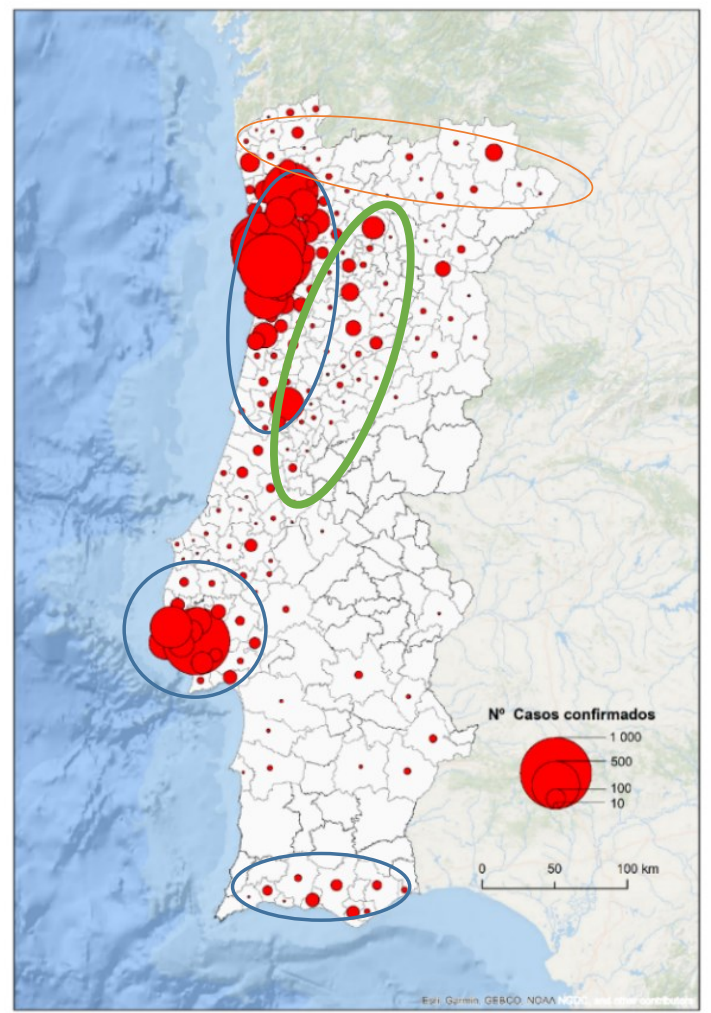

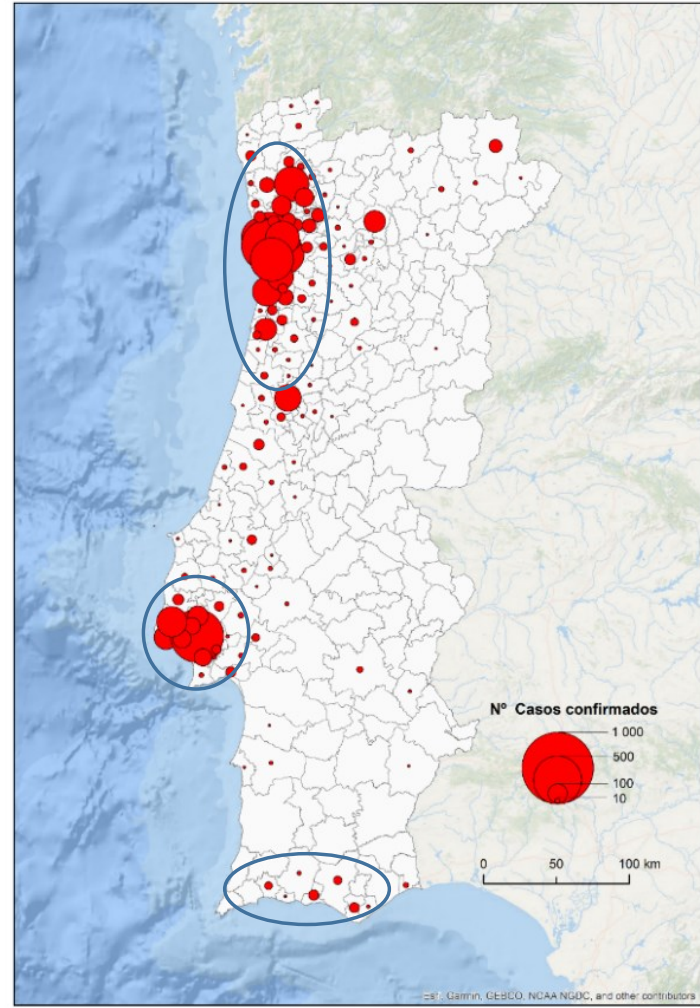

$25 / 04 / 2020$

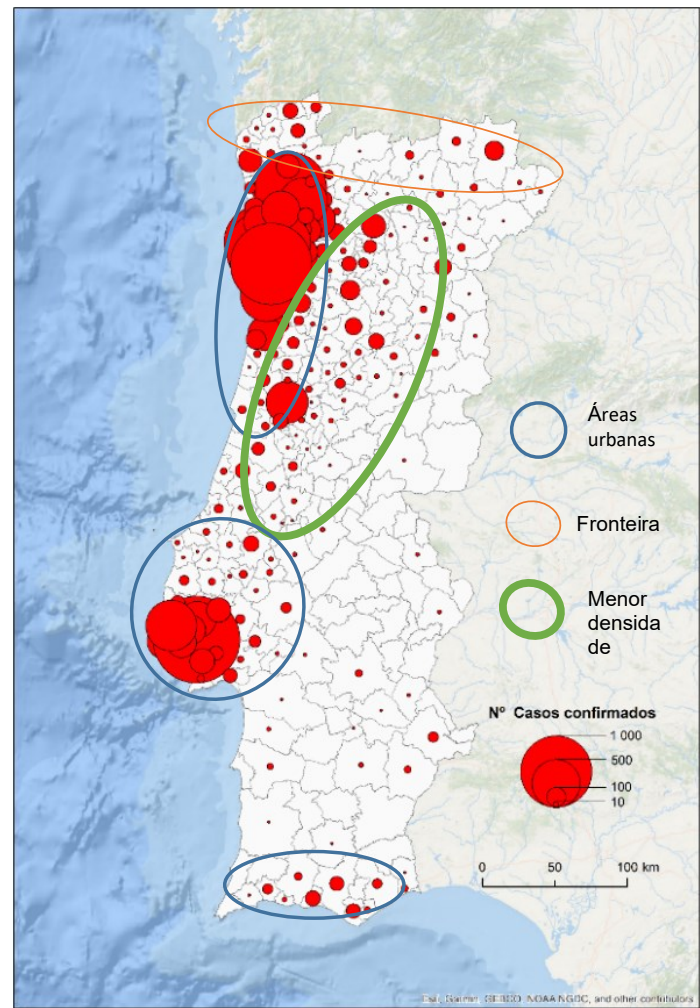

Fonte: DGS 2020: https://covid19.min-saude.pt/ponto-de-situacao-atual-em-portugal/ In Marques da Costa, N.; Marques da Costa, E. (2020c) 
Figura 2 - Número de casos confirmados por 10000 habitantes (concelhos com 3 ou mais casos) $24 / 03 / 2020$ $01 / 04 / 2020$

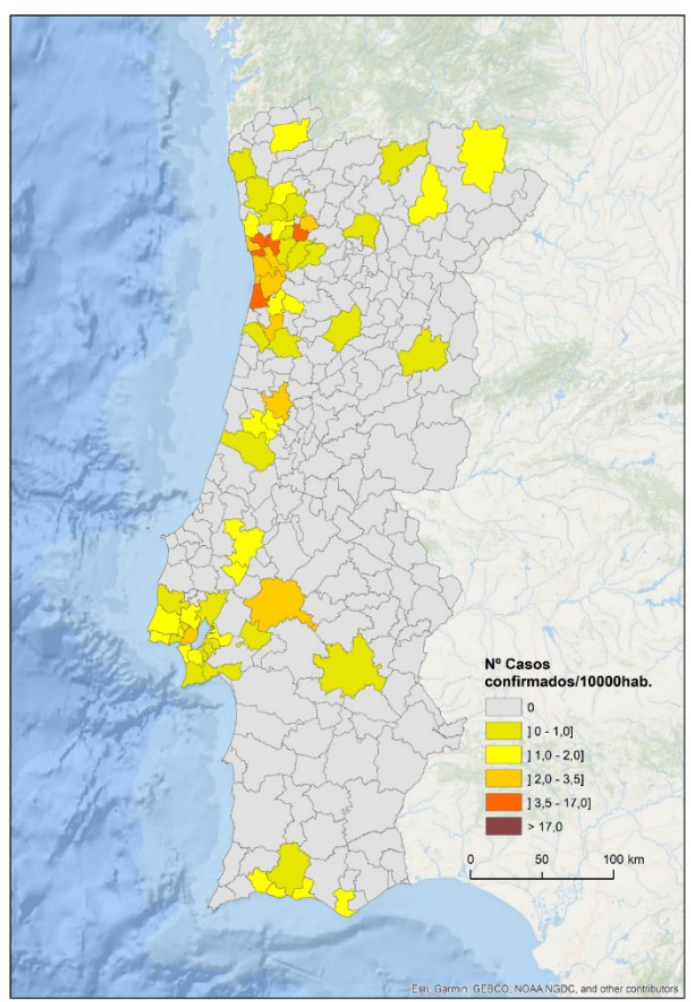

$12 / 04 / 2020$

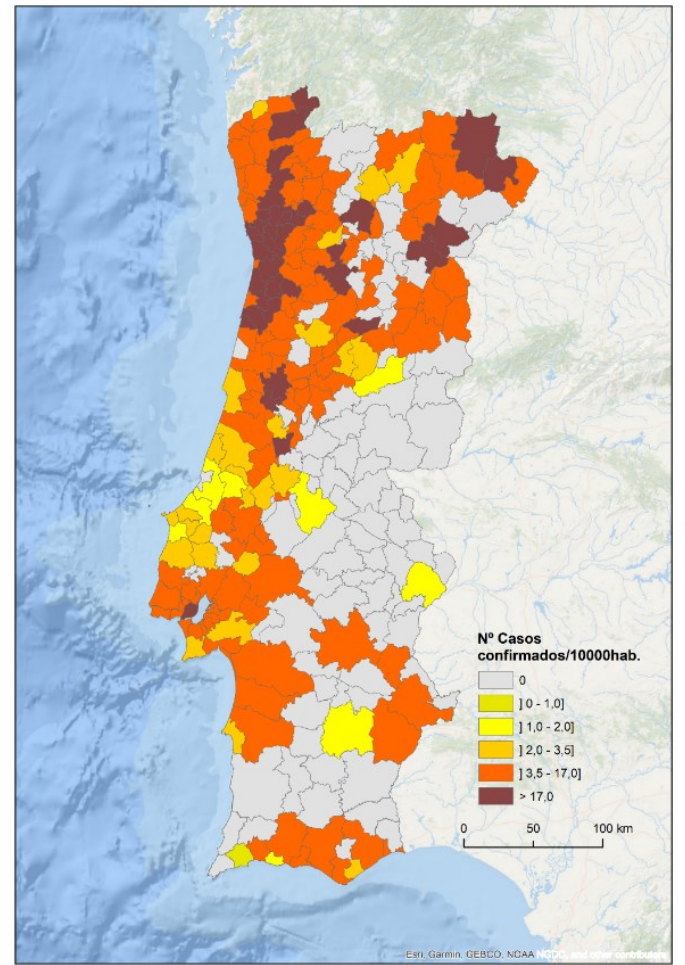

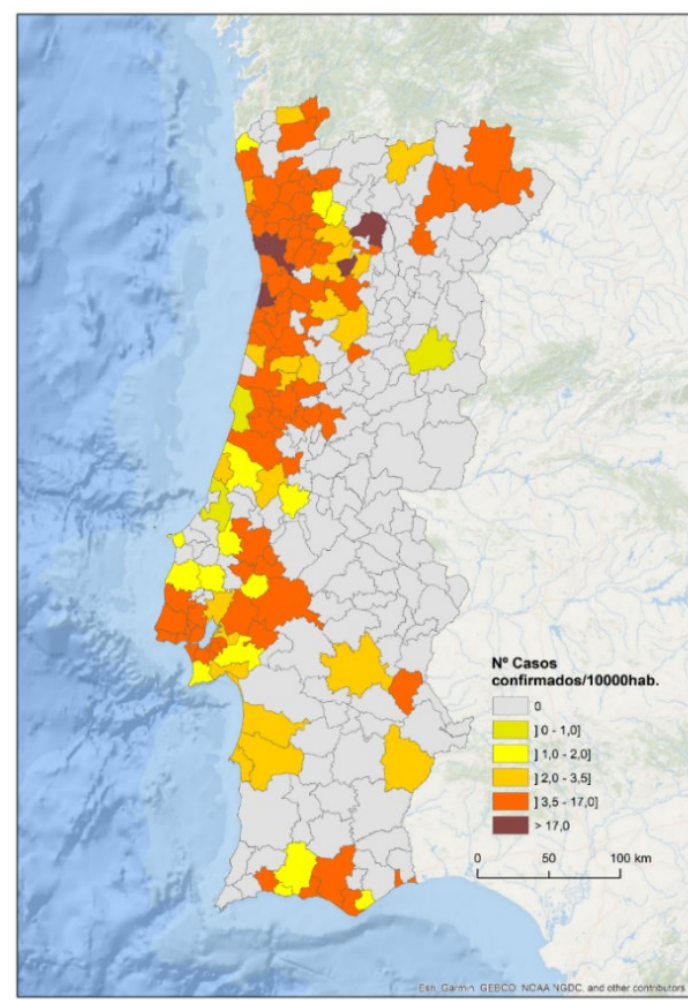

$25 / 04 / 2020$

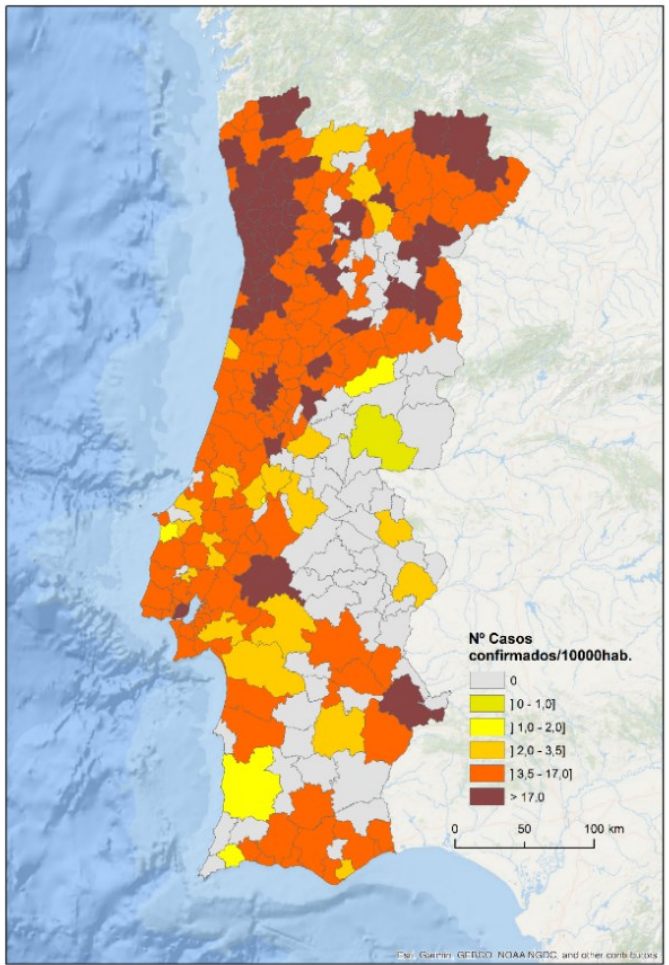

Fonte: DGS 2020: https://covid19.min-saude.pt/ponto-de-situacao-atual-em-portugal/ In Marques da Costa, N.; Marques da Costa, E. (2020c) 
Tabela 2 - Ranking dos 10 concelhos com mais casos confirmados/10 000 habitantes

\begin{tabular}{|c|c|c|c|c|c|c|c|}
\hline Concelhos & $25 / 03$ & Concelhos & $12 / 04$ & Concelhos & $17 / 04$ & Concelhos & $25 / 04$ \\
\hline Ovar & 10,2 & Porto & 42,8 & V. N. Foz Côa & 128,4 & $\begin{array}{l}\text { V. N. Foz } \\
\text { Côa }\end{array}$ & 122,3 \\
\hline Maia & 7,6 & Lisboa & 17,8 & Ovar & 93,1 & Ovar & 104,2 \\
\hline Valongo & 6,7 & V. N. Gaia & 28,1 & Castro Daire & 71,8 & Castro Daire & 74,0 \\
\hline Lousada & 6,2 & Matosinhos & 41,0 & Valongo & 60,1 & Valongo & 72,5 \\
\hline Porto & 5,9 & Gondomar & 42,3 & Resende & 57,6 & Resende & 64,4 \\
\hline Lisboa & 3,5 & Braga & 35,6 & Maia & 54 & Maia & 60,0 \\
\hline Gondomar & 3,4 & Maia & 43,6 & Gondomar & 49,5 & Gondomar & 58,3 \\
\hline Matosinhos & 3,1 & Valongo & 50,8 & Matosinhos & 49,3 & Matosinhos & 58,3 \\
\hline Felgueiras & 3,0 & Ovar & 76,9 & Porto & 48,3 & Porto & 56,3 \\
\hline Espinho & 2,7 & Sintra & 10,2 & Braga & 45,7 & Braga & 56,0 \\
\hline Coimbra & 2,5 & S. M. Feira & 20,1 & V. Cambra & 39,7 & Felgueiras & 54,4 \\
\hline S. M. Feira & 2,4 & Coimbra & 20,6 & Felgueiras & 38,7 & V. Cambra & 47,7 \\
\hline
\end{tabular}

- Mais recentemente, com um desfasamento de umas semanas, a situação dos lares de idosos no norte e centro, replica-se aos concelhos envelhecidos do Oeste e do Médio Tejo e de seguida a Lisboa e sul do país. Aqui importa sublinhar a relevância da cidade de Lisboa, que regista valores de envelhecimento populacional muito elevados.

\section{Correntes migratórias:}

- Por um lado, temos de considerar o regresso/visita de emigrantes. Cruzando o padrão anterior com o registo de casos importados de países onde existe corrente de emigração portuguesa (os dados citados anteriormente), podemos inferir que ao fenómeno de contágio interno decorrente da manutenção da atividade económica e contatos com regiões infetadas, se associou o forte afluxo de emigrantes que se deslocaram para Portugal, ora com o argumento das férias da Páscoa, ora por razões de visita aos familiares ou, ainda, por razões de fuga dos países onde estão emigrados, que registavam valores bastante superiores, bem como pelo resultado da interrupção das atividades profissionais;

- Cabe realçar o recente alargamento do número de infetados entre a população imigrante.

\section{CONCLUSÕES}

A difusão da COVID-19 em Portugal relaciona-se com a hierarquia da rede urbana, difundindo-se a infeção a partir destes centros urbanos principais para outros aglomerados próximos. Para além das áreas metropolitanas e maiores cidades, o padrão parece refletir, em parte, pois há sempre uma dimensão acidental, a inserção internacional de alguns sistemas de produção industrial do norte e centro litoral, com dinâmica exportadora e importadora com outros países da Europa onde o surto da COVID-19 foi mais precoce e intenso é uma explicação relevante. Para além destas dinâmicas, contamse outros fatores como as deslocações diárias realizadas entre concelhos de residência e de trabalho.

Por outro lado, a dinâmica de contágio aos lares de idosos, fortemente representados por populações com idades nos grupos etários superiores a 75 anos, são outro território altamente vulnerável. A entrada do vírus nestes lugares pode ter 3 origens: visitas de familiares infetados, infeção das cuidadoras e outro pessoal, e contágio por deslocação dos idosos a hospitais ou outras unidades de saúde para a realização de exames.

Por fim, encontramos uma crescente incidência nos imigrantes, nomeadamente refugiados, residentes em hostels e alojamentos precários com grande proximidade, fomentadora do contágio. Essa situação afeta particularmente Lisboa. 
Figura 3 - População residente em cidades, 2013

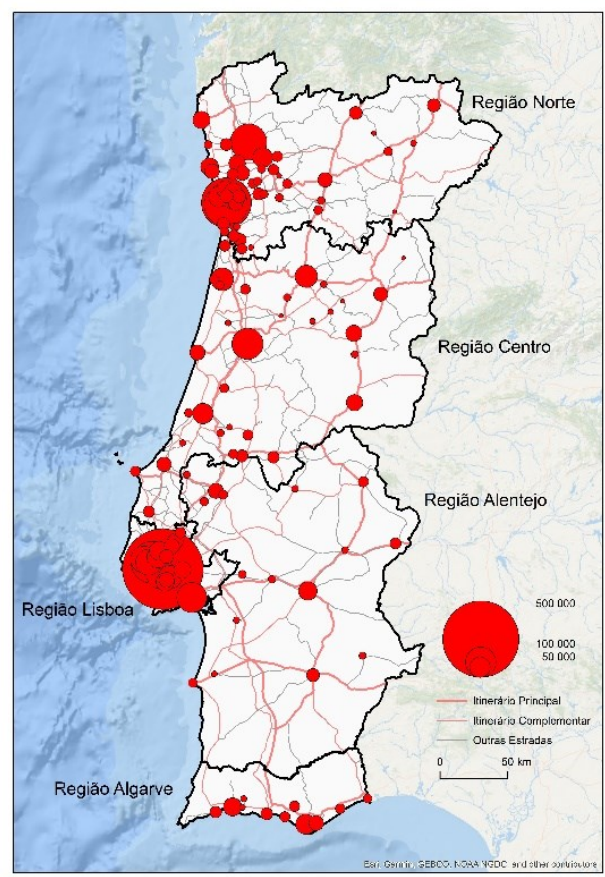

Fonte: INE, Sistema integrado de nomenclaturas estatísticas

Figura 5 - Índice de envelhecimento por concelho, 2018

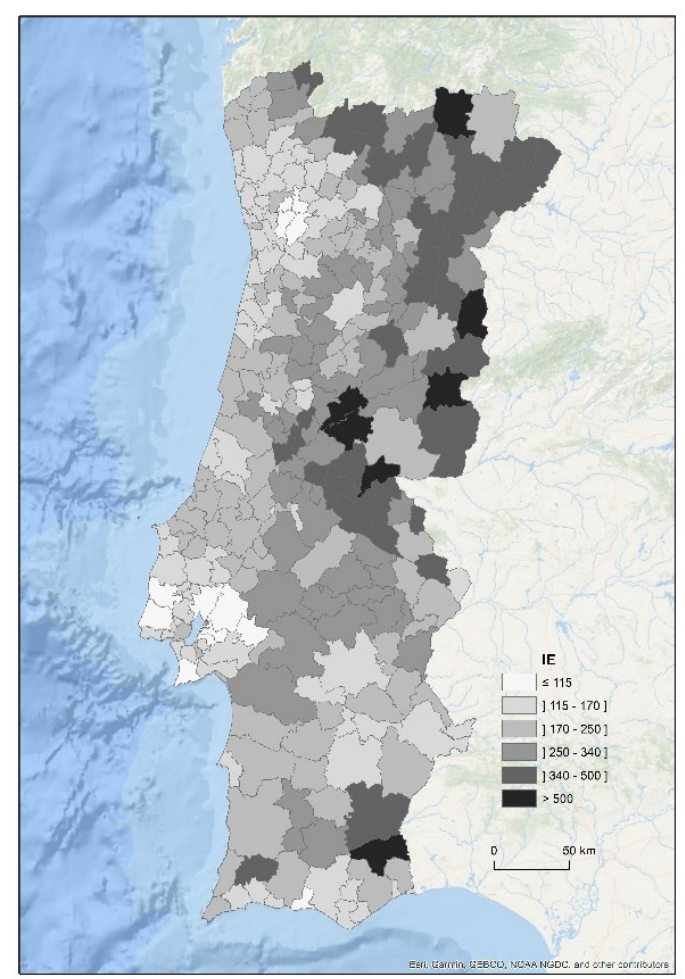

Fonte: INE, Estimativas anuais da População Residente
Figura 4 - Densidade Populacional por concelho, 2018

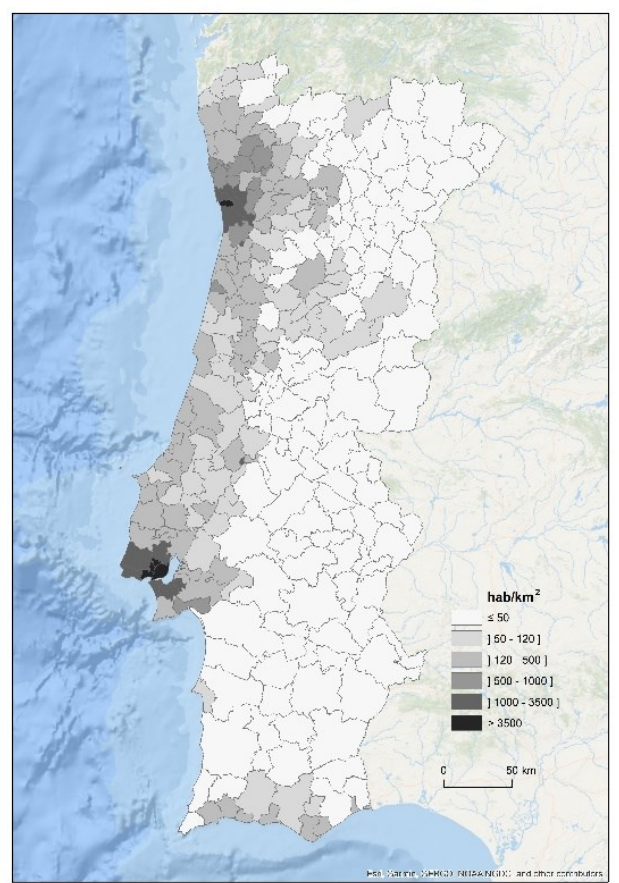

Fonte: INE, Estimativas anuais da População Residente

Figura 6 - № de empregados por concelho, 2018

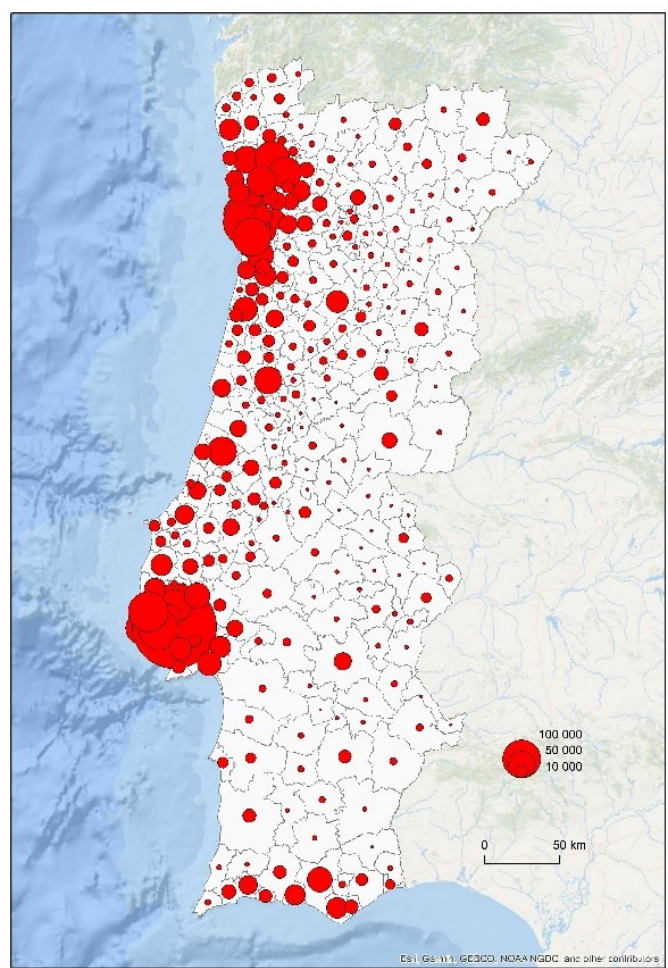

Fonte: INE, Sistema de contas integradas das empresas 
A presente evolução do padrão geográfico, apresenta uma relação com as características demográficas e socioeconómicas dos territórios, mas o padrão diferenciado de velocidade e dinâmica de propagação, demonstra a não linearidade do fenómeno, dificultando a estimação de cenários futuros. Neste contexto, a pressão e efetivação da ação de testar mantem-se pertinente, mas estamos agora numa nova fase que procura conhecer o grau de imunidade da população portuguesa. Portugal iniciou o desconfinamento no dia 4 de maio, com um plano de retoma de atividades graduais. Contudo, as interrogações para o futuro são mais que muitas, constituindo um enorme desafio, talvez o maior das suas vidas, para populações e entidades públicas.

\section{REFERÊNCIAS}

DGS. Ponto de Situação Atual em Portugal. Lisboa: MS-DGS. 2020 https://covid19.min-saude.pt/pontode-situacao-atual-em-portugal/ (acesso diário desde 25 de Março de 2020)

DGS. Plano Nacional de Preparação e Resposta à Doença por novo coronavírus (COVID-19), Coord. Rita Sá Machado, Lisboa: MS-DGS. 2020b

DGS. Novo Coronavirus-COVID 19. Relatórios de situação. Lisboa: MS-DGS. 2020c https://covid19.min-saude.pt/relatorio-de-situacao/ (acesso diário desde 2 de Março de 2020)

MARQUES DA COSTA, N.; MARQUES DA COSTA, E. COVID 19 - Expressão geográfica do número de casos confirmados em Portugal: 1 de Abril 2020. Lisboa: CEG. 2020 http://hdl.handle.net/10451/43020

MARQUES DA COSTA, E.; MARQUES DA COSTA, N. COVID 19 - Expressão geográfica do número de casos confirmados em Portugal, Boletim No 2 - 14 de Abril de 2020, Lisboa, CEG, 2020b http://hdl.handle.net/10451/43021

MARQUES DA COSTA, E.; MARQUES DA COSTA, N. COVID 19 - Expressão geográfica do número de casos confirmados em Portugal, Boletim No 3 - 29 de Abril de 2020, Lisboa, CEG, 2020C http://hdl.handle.net/10451/43253

WHO. Ten threats to global health in 2019. WHO. 2019. https://www.who.int/news-room/featurestories/ten-threats-to-global-health-in-2019 (acesso em 22 de Março de 2020)

WHO. Coronavirus disease (COVID-19) outbreak situation. WHO. 2020. https://experience.arcgis.com/experience/685d0ace521648f8a5beeeee1b9125cd (acesso diário desde 25 de Março de 2020)

WHO. COVID-19 situation in the WHO European Region, WHO. $2020 \mathrm{~b}$. https://who.maps.arcgis.com/apps/opsdashboard/index.html\#/ead3c6475654481ca51c248d52ab9c61 (acesso diário desde 25 de Março de 2020). 